\title{
Does wood biomass energy use reduce CO2 emissions in European Union member countries? Evidence from 27 members
}

\begin{abstract}
This study investigates the effect of wood biomass energy consumption on $\mathrm{CO} 2$ emissions in 27 European Union (EU) member countries for the 1990-2017 period. Applying panel dynamic ordinary least squares (DOLS), the results revealed that $\mathrm{CO} 2$ emissions decline with an increase in wood biomass energy consumption. While fossil fuel, GDP per capita and trade openness are found to be increasing $\mathrm{CO} 2$ emissions. The finding implies that $\mathrm{CO} 2$ emissions in $\mathrm{EU}$ member countries can be effectively reduced by increasing the amount wood biomass energy consumption in production processes. This will eventually contribute to tackling global warming. The estimated results are considered robust as they were validated by panel FMOLS and pooled OLS. The study recommends for EU member countries to increase the share of wood biomass energy in their energy mix to reduce $\mathrm{CO} 2$ emissions. Policy makers in these countries should also invest more in wood biomass energy production to increase its supply and accessibility. The authorities of these countries can equally emphasize on efficiency and sustainability of wood biomass energy to achieve energy security and reduce dependency on fossil fuel.
\end{abstract}

Keyword: Wood biomass energy; CO2 emissions; EU member countries; GDP per capita; Fossil fuel 